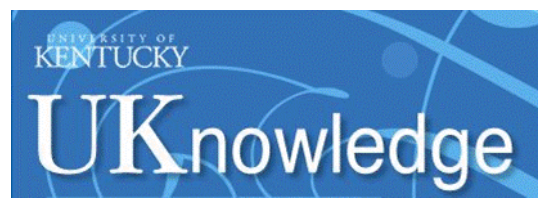

University of Kentucky

UKnowledge

\title{
Sex Differences in the Drinking Response to Angiotensin II (Angll): Effect of Body Weight
}

\author{
Jessica Santollo \\ University of Kentucky, j.santollo@uky.edu \\ Ann-Marie Torregrossa \\ The State University of New York at Buffalo \\ Derek Daniels \\ The State University of New York at Buffalo
}

Follow this and additional works at: https://uknowledge.uky.edu/biology_facpub

Part of the Behavior and Behavior Mechanisms Commons, Biology Commons, and the Hormones, Hormone Substitutes, and Hormone Antagonists Commons

Right click to open a feedback form in a new tab to let us know how this document benefits you.

\section{Repository Citation}

Santollo, Jessica; Torregrossa, Ann-Marie; and Daniels, Derek, "Sex Differences in the Drinking Response to Angiotensin II (AnglI): Effect of Body Weight" (2017). Biology Faculty Publications. 169.

https://uknowledge.uky.edu/biology_facpub/169

This Article is brought to you for free and open access by the Biology at UKnowledge. It has been accepted for inclusion in Biology Faculty Publications by an authorized administrator of UKnowledge. For more information, please contact UKnowledge@lsv.uky.edu. 
Sex Differences in the Drinking Response to Angiotensin II (Angll): Effect of Body Weight

\section{Digital Object Identifier (DOI)}

https://doi.org/10.1016/j.yhbeh.2017.05.013

Notes/Citation Information

Published in Hormones and Behavior, v. 93, p. 128-136.

(C) 2017 Elsevier Inc. All rights reserved.

This manuscript version is made available under the CC-BY-NC-ND 4.0 license https://creativecommons.org/licenses/by-nc-nd/4.0/.

The document available for download is the author's post-peer-review final draft of the article. 


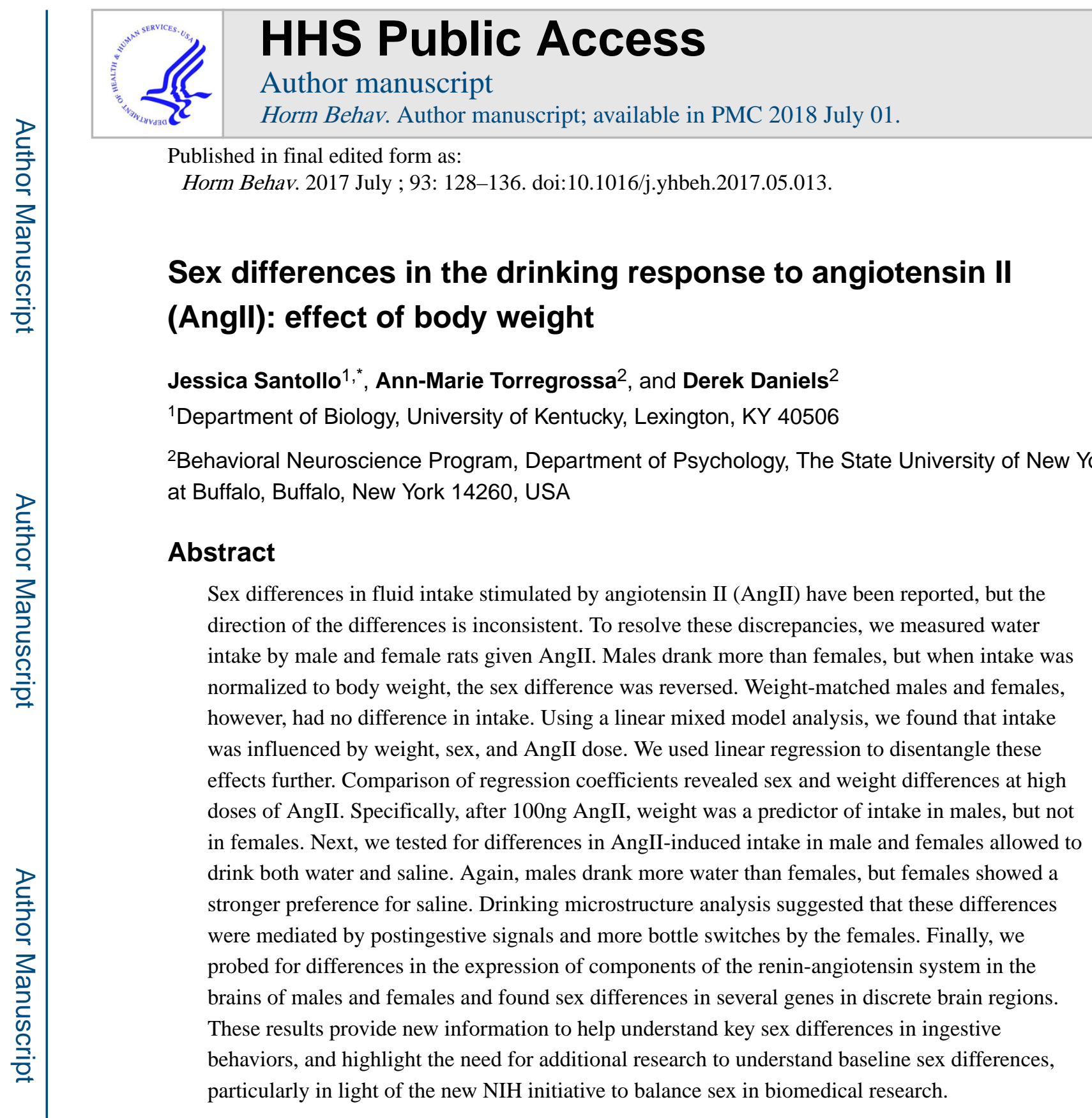

\section{Keywords}

water intake; saline intake; estrous cycle; AT1R

\footnotetext{
"Correspondence to: Jessica Santollo, Department of Biology, University of Kentucky, Lexington, KY 40506, United States. Tel.: 859-323-5156; j.santollo@uky.edu.

Publisher's Disclaimer: This is a PDF file of an unedited manuscript that has been accepted for publication. As a service to our customers we are providing this early version of the manuscript. The manuscript will undergo copyediting, typesetting, and review of the resulting proof before it is published in its final citable form. Please note that during the production process errors may be discovered which could affect the content, and all legal disclaimers that apply to the journal pertain.

Disclosures of interests

The authors declare no conflict of interests.
} 


\section{Introduction}

The renin-angiotensin system (RAS) is a key component of fluid homeostasis.

Under conditions of hypovolemia, a coordinated response of the RAS is initiated to preserve and restore body fluid (Daniels and Fluharty, 2009). The physiological aspects of this response include an increase in blood pressure mediated by the hormone angiotensin II (AngII) and a vasopressin-mediated decrease in urine output (Guyton, 2006). In addition, aldosterone acts on the kidney to promote sodium retention (Guyton, 2006). These physiological responses help the body maintain function in the face of reduced volume, but a behavioral response is needed to restore volume. Accordingly, in addition to these physiological responses, AngII increases drinking of both water and saline (Epstein et al., 1970; Fitzsimons and Simons, 1969; Hsiao et al., 1977). Although the physiological and behavioral responses to hypovolemia have been well studied, many open questions remain, including questions about the effect of sex on the system.

There are clear sex differences in both the physiological and behavioral responses to activation of the RAS. For example, AngII produces a stronger increase in blood pressure in males than it does in females (Tatchum-Talom et al., 2005; Xue et al., 2013), an effect mediated by the ovarian hormone estradiol acting, at least in part, through estrogen receptor alpha (ERa) (Xue et al., 2005; Xue et al., 2007b) and by testosterone acting via androgen receptors (Xue et al., 2007a; Xue et al., 2005). Fluid intake stimulated by AngII is also affected by sex, however, there are conflicting reports in the literature about the direction of this sex difference and many unanswered questions remain. For example, when hormones are experimentally manipulated, estradiol-primed OVX females were found to drink less than males (Jonklaas and Buggy, 1984), but earlier studies reported that cycling females, in all stages of the estrous cycle, drank more than males (Kaufman, 1980; Vijande et al., 1978). Finally, others have reported no sex difference in fluid intake after AngII treatment (Sun et al., 1996). The reason for the apparent discrepancy is not clear and the lack of an effect in some studies is surprising given the well documented effects estrogens have on inhibiting AngII-stimulated fluid intake (Curtis, 2009; Krause et al., 2003; Santollo and Daniels, 2015a, b; Santollo et al., 2016). Because females have higher levels of circulating estrogens than males, and estrogens tonically inhibit fluid intake (Jarrar et al., 2000; Overpeck et al., 1978; Tarttelin and Gorski, 1971), it is reasonable to predict that AngII-stimulated fluid intake would be greater in males than females, and difficult to reconcile the discrepancy in the literature.

Several issues could contribute to the discrepancies in literature about the previously reported sex differences (or lack of differences) in AngII-stimulated fluid intake. For instance, some of these studies normalized fluid intake to body weight (Kaufman, 1980; Sun et al., 1996), but males have greater body mass and it is unknown if, and to what degree, this contributes to the observed sex difference. Furthermore, the earlier studies used single doses of AngII; therefore, it is unclear if differences would be revealed if other parts of a doseresponse curve were tested. Finally, these studies only measured total fluid intake without any attention given to drinking patterns that could be different, without affecting total fluid consumption. This is a potentially important oversight because studies of drinking 
microstructure can reveal differences and suggest more details about the nature of such differences. Accordingly, we conducted a set of experiments designed to examine how each of these issues influence AngII-stimulated drinking in males and females.

The studies in this report tested the overarching hypothesis that fluid intake stimulated by AngII differs between males and females. To this end, we measured the drinking response after injection of a range of doses of AngII in male and estrous female rats, and also investigated the role of body weight in water intake. We limited our testing to male rats and female rats in estrus to focus on a time in the cycle during which estrogens influence intake (Danielsen and Buggy, 1980). Furthermore, earlier studies found that female rats, either in estrus or diestrus, drank more than did male rats, obviating the need to include both estrus and diestrus females the present study design (Vijande et al., 1978). Because AngII stimulates saline intake in addition to water intake (Daniels and Fluharty, 2009), we performed additional experiments using two-bottle tests to measure the dose-response relationship between AngII and intake when both water and saline were available. Moreover, we analyzed drinking microstructure to help identify mechanism(s) by which sex influences intake. Finally, we probed for differences in a number of RAS-relevant genes in females and age- and body weight-matched males in multiple areas of the brain involved in controlling fluid intake and blood pressure.

\section{Methods}

\section{Animals and housing}

Male and female Sprague Dawley rats (Envigo Laboratories, Indianapolis, IN) were used in all of the studies described. For behavioral experiments (Experiments 1 and 2), rats were singly housed in hanging wire-mesh stainless steel cages with ad libitum access to food (Teklad 2018; Harlan Laboratories) and tap water unless otherwise noted. Rats in 2-bottle intake tests (Experiments 2) had access to an additional bottle containing a $1.5 \%$ saline solution. Rats in Experiment 3 were singly housed in standard plastic cages with ad libitum access to food and tap water. Body weight was monitored daily. Vaginal cytology was monitored daily as previous described (Becker et al., 2005; Santollo and Eckel, 2008) and cycle stage corresponded to a $12 \mathrm{~h}$ dark phase and the following $12 \mathrm{~h}$ light phase (i.e., estrous included the $12 \mathrm{~h}$ dark phase during which time females are sexually receptive and decrease ingestive behaviors along with the following $12 \mathrm{~h}$ light phase). All testing occurred in the rats' home cages during the early part of the light phase. Males and females were housed in separate colony rooms but testing occurred during the same timeframe. The temperature- and humidity-controlled colony rooms were maintained on a 12:12 h light-dark cycle (lights on at $0800 \mathrm{~h}$ ). All experimental protocols were approved by the Animal Care and Use Committee at the University of Buffalo, and the handling and care of the animals was in accordance with the National Institute of Health Guide for the Care and Use of Laboratory Animals.

\section{Surgery}

All animals underwent stereotaxic surgery to implant a chronic cannula aimed at the right lateral ventricle following standard laboratory procedures. Briefly, rats were anesthetized 
with an injection of a ketamine [i.m., $75 \mathrm{mg} / \mathrm{kg}$ (males), $80 \mathrm{mg} / \mathrm{kg}$ (females); Fort Dodge Animal Health, Fort Dodge, IA] and xylazine [i.m., $5 \mathrm{mg} / \mathrm{kg}$ (males), $4.5 \mathrm{mg} / \mathrm{kg}$ (females); Akron Inc., Decatur, Il]. The rat's head was shaved and secured into a stereotaxic frame. A small incision was made on top of the skull, a small hole was drilled, and a 26-gauge guide cannula was implanted using the following coordinates: $0.9 \mathrm{~mm}$ posterior and $1.4 \mathrm{~mm}$ lateral to bregma, and $2.8 \mathrm{~mm}$ ventral to the skull. The cannula was fixed to the skull with bone screws and dental cement. All rats received a single injection of carprofen (sc, $5 \mathrm{mg} / \mathrm{kg}$; Pfizer Animal Health, New York, NY) after surgery to minimize pain and a single injection of isotonic saline (sc, $5 \mathrm{ml}$ ). One week later, accurate cannula placement was verified by measuring the drinking response to an injection of $10 \mathrm{ng}$ Ang II. Only rats that drank at least $6 \mathrm{ml}$ in $20 \mathrm{~min}$ after Ang II-treatment were included in the study.

\section{Fluid intake measures}

Total intake was calculated by weighing the water bottles before and after each test period. Licking behavior was measured using a contact lickometer (designed and constructed by the Psychology Electronics Shop, University of Pennsylvania, Philadelphia, PA) that recorded individual licks to allow for analysis of drinking microstructure. The lickometer interfaced with a computer using an integrated USB digital I/O device (National Instruments, Austin, TX). Home cages were affixed with an electrically isolated metal plate with a $3.175-\mathrm{mm}$ wide opening, through which the rat needed to lick to reach the drinking spout, minimizing the possibility of nontongue contact with the spout.

\section{cDNA synthesis and RT-PCR}

Real-time PCR was used to quantify AT1R, ACE1, ACE2, and renin mRNA levels in samples from the periventricular tissue surrounding the anteroventral third ventricle (AV3V), subfornical organ (SFO), paraventricular nucleus of the hypothalamus (PVN), nucleus of the solitary tract (NTS), and rostroventral lateral medulla (RVLM). DNA-free total RNA was purified using the E.Z.N.A. MicroElute Total RNA Kit (Omega Bio-Tek Inc, Norcross, GA), including a deoxyribonuclease step. Reverse transcription (RT) was performed with $500 \mathrm{ng}$ of RNA using the iScript cDNA Synthesis Kit (Bio-Rad, Hercules, CA). Real-time PCR was carried out using SYBR GREEN gene master mix (Bio-Rad, Hercules, CA) according to the manufacturer's instructions. 18s was used as an internal control for quantification of mRNA. The primer sequences used are listed in Table 1.

\section{Experiment 1 Does Angll-induced water intake vary as a function of body} weight or sex?-Using a repeated measures, counterbalanced design, approximate agematched (within 3 weeks of age) male and estrous female rats received intracerebral ventral (i.c.v.) injections of $0,1,10,50$, or 100ng AngII dissolved in $1 \mu$ t tris buffered saline (TBS) every four to five days. Water intake during the subsequent $2 \mathrm{~h}$ was monitored. Food was removed from the cages during the $2 \mathrm{~h}$ test period. In a subsequent experiment, body weight matched $(285 \mathrm{~g})$ male and estrous female rats received a single i.c.v. injections of $100 \mathrm{ng}$ AngII and the subsequent $2 \mathrm{~h}$ fluid intake was measured. Again, food was removed during the test period. Estrous females were used in all experiments because during this time period endogenous estrogens reduce fluid intake (Danielsen and Buggy, 1980), making this the 
most likely phase of the estrous cycle when differences between males and females could be observed.

\section{Experiment 2. Do the patterns of water or saline intake after Angll vary as a} function of sex?-Using a repeated measures, counterbalanced design, approximate agematched (within 3 weeks of age) male and estrous female rats received 1- $\mu$ i.c.v. injections of $0,1,10,50$, or $100 \mathrm{ng}$ AngII every four to five days. Water and $1.5 \%$ saline intake during the subsequent $2 \mathrm{~h}$ was monitored. Food was removed from the cages during the $2 \mathrm{~h}$ test period.

\section{Experiment 3. Does central expression of RAS genes vary as a function of sex}

or body weight?-Estrous females and age- (135 day) and body weight-matched ( $245 \mathrm{~g}$ ) male rats were anesthetized in the early part of the light cycle with exposure to $90 \mathrm{~s}$ isoflurane and decapitated. Brains were immediately removed from the skull, flash frozen with 2-methyl-butane (Sigma-Aldrich, St. Louis, MO) and stored at $-80^{\circ} \mathrm{C}$. The AV3V, SFO, PVN, NTS, and RVLM regions of the brain were obtained by sectioning $300 \mu \mathrm{m}$ coronal sections on a cryostat and then taking four $1 \mathrm{~mm}$ punches from each brain region. Tissue punches were stored at $-80^{\circ} \mathrm{C}$ until processing for mRNA content by RT-PCR.

\section{Data Analysis}

All data are presented as means \pm SEM. Saline preferences was calculated by dividing the amount of saline consumed by the amount of total fluid consumed. Drinking microstructure analysis was processed in a MATLAB (MathWorks, Natick, MA) software environment before being ported to Excel (Microsoft, Redmond, WA) for final analysis. A burst was defined as at least two licks with an interlick interval (ILI) of no more than $1 \mathrm{sec}$. Burst size was defined as the average number of licks within a burst. RT-PCR values were calculated using the $\Delta \Delta$ CT quantification method with 18 s as the normalizing housekeeping gene. Statistical analyses were performed using Statistica (StatSoft, Tulsa, OK). Water and saline intakes, water intake normalized to $100 \mathrm{~g}$ body weight, total fluid intake, and saline preference in Experiments 1 and 2 were analyzed using a two factor-mixed design ANOVA (Sex X Dose). Using linear mixed model analysis we compared a number of potential models which included, dose, body weight, sex and age, we began with a model containing all factorial interactions and systematically reduced the model to only main effects. Our best fit model was chosen by comparing Akaike's Information Criterions (AIC). Linear regressions were conducted to determine the relationship between body weight and sex for males and females after each dose of AngII and regression coefficients were compared to the null hypothesis that males and females are equal. T-tests were used to compare water intake in body weight-matched males and females in Experiment 1 and drinking microstructure in Experiment 2. In addition, a three factor ANOVA (Sex X Fluid X Time) was used to analyze water and saline intake across time in males and females in Experiment 2. Changes in mRNA were analyzed using one-way ANOVAs for each brain region. Newman Keuls post hoc tests were used throughout to determine individual group differences after significant main or interaction ANOVA effects. Cohen's d effect size was calculated using the Campbell Collaboration Effect Size Calculator and $\eta^{2}$ was calculated for all ANOVAs as the $\mathrm{SS}_{\text {effect }} /\left(\mathrm{SS}_{\text {Total }}\right)$. 


\section{Results}

\section{Experiment 1. Does Angll-induced water intake vary as a function of body weight or sex?}

Dose-response curves to central treatment of AngII were generated for male and estrous female rats. Sex affected both water intake and water intake normalized to body weight. Analysis of water intake (Fig 1A) revealed a significant main effect of $\operatorname{sex}\left(\mathrm{F}_{1,17}=12.34, p\right.$ $\left.<0.001, \eta^{2}=0.42\right)$, dose $\left(\mathrm{F}_{4,68}=201.50, p<0.001, \eta^{2}=0.90\right)$, and an interaction between sex and dose $\left(\mathrm{F}_{4,68}=4.48, p<0.05, \eta^{2}=0.02\right.$; Fig. 1A $)$. Males drank more water than females after treatment with 10,50, and 100ng AngII $(p<0.05)$. When water intake was normalized to $100 \mathrm{~g}$ body weight to control for the differences in mass between sexes the analysis revealed a main effect of sex $\left(\mathrm{F}_{1,17}=7.07, p<0.05, \eta^{2}=0.29\right)$ and dose $\left(\mathrm{F}_{4,68}=\right.$ $\left.162.11, p<0.001, \eta^{2}=0.90\right)$ but no interaction between sex and dose $\left(\mathrm{F}_{4,68}=1.36, p<\right.$ $0.05, \eta^{2}=0.01$; Fig. 1B). Regardless of dose, when intake was normalized to body weight females drank more than males $(p<0.05)$. When body-weight matched males $(285.9 \mathrm{~g}$ $\pm 5.01)$ and estrous females $\left[284.5 \mathrm{~g} \pm 3.61 ;\left(\mathrm{t}_{16}=0.24, p=\right.\right.$ n.s., $\left.\left.\mathrm{d}=0.11\right)\right]$ were treated with 100ng AngII, water intake did not differ between the groups, $\left(\mathrm{t}_{16}=0.92, p=\mathrm{n} . \mathrm{s} ., \mathrm{d}=0.43\right.$; Fig. 1C). These animals, as expected, significantly differed in age, males $76 \pm 0$ vs. females $182 \pm 9.2$ days $\left(\mathrm{t}_{16}=11.55, p<0.001, \mathrm{~d}=4.43\right)$.

Using the data from Experiment 1, we ran a linear mixed model analysis to determine which variables were the best predictors of intake. The best fitting model (AIC 316.104) included body weight, sex, age, and dose as main effects and sex $\mathrm{X}$ dose, sex $\mathrm{X}$ body weight, dose $\mathrm{X}$ body weight, sex $\mathrm{X}$ dose $\mathrm{X}$ body weight interaction terms. Body weight $\left(\mathrm{F}_{1,82}=8.684, p<\right.$ $0.05)$ and an interaction between sex and dose $\left(\mathrm{F}_{2,82}=3.193, p<0.05\right)$ as significant predictors of intake. In this model main effects of sex $\left(\mathrm{F}_{1,82}=0.023, p=\mathrm{n}\right.$.s.), age $\left(\mathrm{F}_{1,82}=\right.$ $3.795, p=$ n.s. $)$, dose $\left(\mathrm{F}_{2,82}=0.809, p<\right.$ n.s. $)$ or interactions between sex and bodyweight $\left(\mathrm{F}_{1,82}=0.133, p=\right.$ n.s. $)$, dose and body weight $\left(\mathrm{F}_{2,82}=1.283, p=\right.$ n.s. $)$, or sex, dose and body weight $\left(\mathrm{F}_{2,82}=2.736, p=\mathrm{n}\right.$.s. $)$ were not predictive of intake. Next, we analyzed regressions between body weight and intake for each sex after treatment with 10,50, and 100ng AngII. Body weight was not predictive of water intake after 10ng AngII-treatment in either males ( $\mathrm{r}=0.26, p=\mathrm{n} . \mathrm{s}$.) or estrous females $(\mathrm{r}=0.03$, $p=$ n.s.; Fig $2 \mathrm{~A})$, nor after $50 \mathrm{ng}$ AngII-treatment in either males $(\mathrm{r}=0.48, p=$ n.s. $)$ or estrous females $(\mathrm{r}=0.59, p=\mathrm{n}$.s.; Fig 2B). Body weight was predictive of water intake after 100ng AngII-treatment in males ( $\mathrm{r}=$ $0.72, p=0.001)$, but not females ( $\mathrm{r}=0.001, p=\mathrm{n}$.s.; Fig $2 \mathrm{C})$. Furthermore, comparison of the regression coefficients between body weight and intake after 100ng AngII revealed a significant difference between males and females (beta $=0.034, p<0.05$ ).

To normalize water intake after 100ng AngII in females to males we generated an equation to correct for the differences between sexes (Corrected Intake $=$ (intake - difference at $\mathrm{y}$ intercept (9.28)) + (body weight $\times$ difference between slopes $(0.03))$ ). This equation allows us to control for differences in sensitivity to the drug across body weights in the different sexes. Analysis of the dose response curve to AngII-stimulated water intake with female intake normalized to males (Fig. 3) revealed a main effect of $\operatorname{sex}\left(\mathrm{F}_{1,17}=15.95, p<0.001\right.$, $\left.\eta^{2}=0.48\right)$, dose $\left(F_{4,68}=190.41, p<0.001, \eta^{2}=0.89\right)$, and an interaction between sex and 
dose $\left(\mathrm{F}_{4,68}=6.55, p<0.001, \eta^{2}=0.03\right)$. Males drank more water than females after treatment with 10, 50, and 100ng AngII ( $p<0.05)$.

\section{Experiment 2. Do the patterns of water or saline intake after Angll vary as a function of sex?}

AngII is also a potent stimulator of saline intake, therefore we also generated dose response curves to central treatment of AngII for male and estrous female rats with access to both water and $1.5 \%$ saline. Fluid intake after AngII-treatment varied as a function of sex. Similar to that reported in Experiment 1, analysis of water intake revealed main effects of sex $\left(\mathrm{F}_{1,16}\right.$ $\left.=10.14, p<0.01, \eta^{2}=0.39\right)$, dose $\left(\mathrm{F}_{4,64}=116.74, p<0.001, \eta^{2}=0.84\right)$, and an interaction between sex and dose $\left(\mathrm{F}_{4,64}=6.21, p<0.001, \eta^{2}=0.05\right.$; Fig. 4A). Males drank more water than females after treatment with 10,50, and 100ng AngII $(p<0.05)$. Analysis of saline intake detected a main effect of dose of AngII $\left(\mathrm{F}_{4,64}=26.23, p<0.001, \eta^{2}=0.61\right)$, but not sex $\left(\mathrm{F}_{1,16}=1.45, p<\right.$ n.s., $\left.\eta^{2}=0.08\right)$, or an interaction between sex and dose $\left(\mathrm{F}_{4,64}=0.45, p\right.$ $<$ n.s., $\eta^{2}=0.01$; Fig. 4B). Regardless of sex, intake after treatment with 10ng was higher than intake after 0 and $1 \mathrm{ng}$. Intake after treatment with 50 and 100ng was higher than intake after 10ng $(p<0.05)$. In addition, total fluid intake was affected by dose of AngII $\left(\mathrm{F}_{4,64}=\right.$ 99.14, $\left.p<0.001, \eta^{2}=0.84\right)$, but did not vary as a function of $\operatorname{sex}\left(\mathrm{F}_{1,16}=1.24, p<\right.$ n.s., $\eta^{2}=$ $0.07)$, and a sex and dose interaction was not detected $\left(\mathrm{F}_{4,64}=2.47, p<\right.$ n.s., $\eta^{2}=0.02$; Fig. 4C). Similar to saline intake, regardless of sex, total intake after treatment with 10ng was higher than intake after 0 and $1 \mathrm{ng}$. Intake after treatment with 50 and 100ng was higher than intake after 10ng $(p<0.05)$. Preference for saline was calculated and analysis of preference revealed a main effect of sex $\left(\mathrm{F}_{1,16}=4.80, p<0.05, \eta^{2}=0.23\right)$, but not dose $\left(\mathrm{F}_{4,64}=0.86, p\right.$ $<$ n.s., $\left.\eta^{2}=0.05\right)$ or an interaction between sex and dose $\left(F_{4,64}=0.28, p<\right.$ n.s., $\eta^{2}=0.02$; Fig. 5D). Regardless of the dose of AngII, females had a greater preference for $1.5 \%$ saline than males $(p<0.05)$.

To test for differences in drinking patterns between males and females, we performed microstructure analysis for the water and saline intakes after treatment with 10ng AngII. We chose to analyze intake at this dose because Experiment 1 indicated that there was no confounding effect of body weight on intake after 10ng AngII. Drinking microstructure for water and saline varied as a function of sex. Males had more bursts for water than females $\left(\mathrm{t}_{16}=2.28, p<0.05, \mathrm{~d}=1.07\right.$; Fig. 5B). Burst number for saline was not different between males and females $\left(\mathrm{t}_{16}=0.77, p=\right.$ n.s., $\mathrm{d}=0.36$; Fig. $\left.5 \mathrm{~B}\right)$ nor were burst size for water $\left(\mathrm{t}_{16}=\right.$ $0.53, p=$ n.s., $\mathrm{d}=0.25)$ or saline $\left(\mathrm{t}_{16}=1.46, p=\right.$ n.s., $\left.\mathrm{d}=0.69\right)$ different between the sexes (Fig. 5A). Females made more switches between the water and saline bottles, compared to males $\left(\mathrm{t}_{16}=2.17, \mathrm{p}<0.05, \mathrm{~d}=1.02\right.$; Fig. $\left.5 \mathrm{C}\right)$. Finally, analysis of licks at the bottle spouts in 5-min bins during the first hour of the testing period revealed a main effect of time $\left(\mathrm{F}_{11,176}=57.95, p<0.001, \eta^{2}=0.77\right)$, fluid type $\left(\mathrm{F}_{1,16}=9.08, p<0.01, \eta^{2}=0 \ldots 32\right)$, and an interaction between sex, time, and fluid $\left(\mathrm{F}_{11,176}=2.15, p<0.05, \eta^{2}=0.10\right.$; Fig. 5D). During the first two 5-min bins, males had more licks for water than for saline or than females had for either fluid $(p<0.05)$. 


\section{Experiment 3. Does central expression of RAS genes vary as a function of sex or body weight?}

Quantitative real-time PCR was used to investigate baseline difference in central expression of genes involved in the RAS between females and age- and body weight-matched males (Table 2). In the AV3V, females had less ACE1 expression compared to age-matched males $\left(\mathrm{F}_{2,15}=4.93, p<0.05, \eta^{2}=0.41\right)$ and in the PVN, age-matched males and females had more ACE1 expression compared to body-weight matched males $\left(\mathrm{F}_{2,15}=5.18, p<0.05, \eta^{2}\right.$ $=0.41)$. In the PVN, females had less ACE2 expression compared to age-matched males $\left(\mathrm{F}_{2,15}=5.76, p<0.05, \eta^{2}=0.43\right)$. In the NTS, females had less renin expression compared to both groups of males $\left(\mathrm{F}_{2,15}=5.77, p<0.05, \eta^{2}=0.43\right)$. No other differences were detected that varied as a function of sex or body weight in these nuclei.

\section{Discussion}

Sex is an important biological variable that affects numerous physiological processes and behaviors. Unfortunately, there is an inadequate number of studies investigating the role of sex and the mechanisms which underlie these sex differences. For instance, sex critically affects RAS function (Fischer et al., 2002), and studies of AngII-induced drinking can help provide insight into the mechanism of this effect. The results provided here demonstrated that females consumed less water than did males after all effective doses of AngII, resulting in different dose-response curves. The present studies also provide guidance about the need to consider a sex difference in body weight when interpreting fluid intake results. Our findings show that there is not a simple answer to this question. Specifically, we found that, under the conditions tested here, body weight was predictive of water intake only in males after large doses of AngII. We also replicated previous findings showing that females have a greater preference for saline than do males (Flynn et al., 1993) and we extended this with data suggesting that postingestive feedback, as indicated by a change in burst number, and frequency of switching between the water and saline bottles contributed to the observed sex difference in AngII-stimulated fluid intake. Finally, we identified specific regions in the brain where enzymes involved in the conversion of AngII are affected by age and sex, identifying a possible locus involved in the protective effects that youth and being a female have on hypertension (Blenck et al., 2016; Writing Group et al., 2016).

The sex difference in water intake after AngII-treatment differs depending on whether and how body weight has been accounted for. As early as 1929, Richter reported daily water intake to be greater in male, than in female rats (Richter and Brailey, 1929). When, however, he normalized intake to body weight, the sex difference was lost. Conflicting findings on the direction of the sex difference for water intake stimulated by AngII-treatment have also been reported. When AngII-stimulated water intake, measured as uncorrected volume, was compared, estradiol-primed OVX females drank less than males (Jonklaas and Buggy, 1984), but others reported that cycling females drank more than males (Kaufman, 1980; Vijande et al., 1978) or have found no difference between sexes (Sun et al., 1996). The present study could help reconcile this apparent inconsistency. Specifically, we replicated both of these findings, showing that when water intake was analyzed, without correcting for body weight, males consumed more than did estrous females. This occurred at all effective 
doses and therefore produced a different dose-response curve for males and females. When, however, we normalized the intake to body weight, the direction of the sex difference was reversed, revealing that females drank more than did males. We, therefore, compared intake in body weight-matched animals to control for body weight and found no differences in water intake when $285 \mathrm{~g}$ rats were tested, but they were also significantly different in age ( 2.5 months for males and 6 months for females). Because age affects many behaviors, including fluid intake (Thunhorst et al., 2010, 2013; Thunhorst and Johnson, 2003), we hypothesized that age, sex, and body weight affect AngII-stimulated water intake.

Body weight is tightly related to age and sex. We, therefore, cannot disentangle the roles of sex, age and body weight experimentally. To address these factors statistically, we developed a linear mixed model containing all of these factors. Sex and dose of AngII, but not age, affected whether body weight predicted AngII-stimulated water intake. When we further examined these variables, we found that there was no relationship between body weight and water intake after 10 and 50ng AngII. Body weight did, however, predict water intake after 100ng AngII, but only in male rats. This is a novel, and interesting finding that leads to a number of questions including whether activational or organizational effects of gonadal hormones, or genes on the $\mathrm{Y}$ chromosome underlie this sex difference. A female brain is necessary for estrogen's anti-dipsogenic effect on AngII-induced water intake (Jonklaas and Buggy, 1985). It is, therefore, likely that organizational effects in the brain mediate other sex differences in the drinking response to AngII. The other question that will require follow-up is why, in males, did body weight predict water intake after high, but not low, doses of AngII. It is possible that high doses of AngII engage a pressor response that provides additional inhibitory feedback on fluid intake (Evered et al., 1988; Robinson and Evered, 1987), and this concomitant effect of AngII is affected by body weight. Consistent with this, females are less sensitive to the pressor response of AngII (Xue et al., 2013), which might explain why body weight was not predictive of intake in females in the present study. Future studies will be needed to address each of these issues.

To adequately factor in the difference in body weight between males and females we generated an equation based on the regression analysis to normalize intake after treatment with 100ng AngII. The equation took into account two factors that were generated from the regression lines between body weight and water intake after 100ng AngII-treatment. First, we accounted for the slope difference between water intake and body weight, which was greater in males, than females. Next, we accounted for the difference in the Y intercept (baseline) between the male and female regression lines, which was higher in females, than males. This generated an equation that was used to normalize female water intake after 100ng AngII-treatment. Intake after treatment with 10 and 50ng AngII was not corrected because there was not a significant relationship between intake and body weight at these doses. The corrections resulted in a slightly lower water intake value for females and, again, ANOVA revealed that after 10, 50, and 100ng AngII-treatment, females drank less water than did males. This provides additional support for to the conclusion of Jonklaas and Buggy, who reported intake to be greater in males than it was in females (Jonklaas and Buggy, 1984). Estrous females drink less water than males in response to elevated AngII levels. AngII-stimulated water intake varies across the estrous cycle, reaching the nadir during estrus, when the females in this experiment were tested (Danielsen and Buggy, 1980). 
Therefore, it is possible that the sex difference in water intake disappears when females are in diestrus or proestrus. This would suggest that the sex difference is mediated by a phasic effect of ovarian hormones which our experiment was not designed to detect, and hence, is a limitation of the current study. Future studies will be needed to address this issue, which will be a first step in determining if the sex difference is mediated by activational, organizational, or a combination of activational and organizational effects of gonadal hormones.

Furthermore, although body weight does play a role in mediating water intake, this is doseand sex-dependent. Simply correcting for differences in body weights between males and females is not adequate and it is likely that future studies comparing fluid intake between the sexes will need to determine an appropriate correction based on the strength of the dipsogen.

Our decision to normalize data using body weight is worthy of discussion. This decision was based on several factors, most importantly a desire to be consistent with previous studies that explored the effect of sex on AngII-stimulated intake. This was an important consideration because we designed the experiments in part to determine if normalizing by body weight or not normalizing could account for some of the differences observed in the literature.

Although our findings show that weight is one of several factors to consider when comparing intake values between sexes, there are other weight-related factors that we did not consider. For instance, our measures did not account for potential contributions of lean versus non-lean mass ratios. Although this is a limitation of our study, it is notable that previous studies found no differences between lean: non-lean ratios between three and eight month animals (Wolden-Hanson et al., 1999), and that the percent of lean body mass does not differ between male and female rats at six months of age, when maintained on a standard diet (Engelbregt et al., 2004). Given that the ages of the rats in these reports includes the age of rats in our studies, we remain confident that body weight is an appropriate way to normalize intake.

In addition to stimulating water intake, AngII increases saline intake, which also is affected by sex. In the present two-bottle test we, again, found that males consumed more water than did females, but saline and total fluid intake (calculated as the sum of water and saline) were not different between the sexes. Females, however, had a greater preference for saline, compared to male rats. This is not surprising because previous reports demonstrate that females show a stronger saline preference during ab libitum intake (Flynn et al., 1993; Krecek, 1973), a sex difference that is mediated by organizational effects of gonadal hormones (Krecek et al., 1972). Sex differences in drinking microstructure in response to AngII, however, have not been explored until now.

In the present studies we used analysis of licking microstructure to provide insight into the nature of the feedback that contributes to the observed sex difference. This is a useful approach that can help identify behavioral differences that contribute to overall differences in intake. The conclusions drawn from this approach are largely based on work by Davis and colleagues who demonstrated that altering the palatability of a solution changed the size of the licking bursts for a solution, whereas altering postingestive feedback via sham feeding changed the number of bursts for a solution (Davis, 1989; Davis et al., 1999). Here, we found that females had fewer bursts for water, but equivalent burst sizes, compared to males. This suggests that the lower water intake was driven, not by a shift in palatability, but by an 
increase in negative postingestive feedback, i.e. females are more sensitive to the postingestive feedback during water consumption. In addition to the analysis of water intake, we also examined licking patterns for saline and found that the number of bursts for saline was not differentially affected by sex, nor did we find differences in burst size. Accordingly, postingetive feedback appears to contribute to the sex difference in water intake, but we found no reliable changes in drinking microstructure that accounted for the greater preference for saline in females. Analysis of bottle switches, however, showed that females made significantly more switches between bottles compared to males. The different pattern of switching was accompanied by a different overall pattern of intake in which males consumed more water than saline during the first 10 minutes of the test, but females drank equivalent amounts of water and saline during the same time. These different patterns led to different final concentration of saline consumed by males and females. Specifically, the final concentration of saline consumed during the test was $0.7 \%$ in females and $0.4 \%$ in males. This difference in concentration is consistent with findings from previous studies showing that females find salt less aversive than do males (Curtis and Contreras, 2006; Flynn et al., 1993). Future studies are needed, however, to determine if sex differences in saline preference affect drinking patterns, or if sex differences in drinking pattern lead to the observed differences in saline preference. Nevertheless, the present studies complement previous work showing sex differences in fluid intake after a number of dipsogenic/ natriorexigenic stimuli (Santollo and Daniels, 2015b), by providing the first report, to our knowledge, of sex differences in licking microstructure.

In discrete brain nuclei, specific enzymes in the RAS pathway were lower in young animals and females, which could mediate the protective effects youth and being female have on hypertension. Renin is necessary for the conversion of angiotensinogen to angiotensin I and we found lower renin expression in the NTS in females, compared to males. ACE1 is necessary for the conversion of angiotensin I to angiotensin II. We detected lower ACE1 expression in the PVN in young males, compared to older males and females. Two additional differences were observed which may reflect a combined effect of sex and age. In the AV3V females had lower ACE1 compared to age-matched, but not body weightmatched, males. In addition, in the PVN females had lower ACE2, the enzyme necessary for converting angiotensin II to angiotensin 1-7, compared to age-matched, but not body weight-matched, males. To fully identify an interaction between age and sex on expression of these genes, body weight matched females is necessary. Unfortunately, the blunted growth curve in females, compared to males (Bell and Zucker, 1971), makes this impossible without the introduction of confounding variables (such as ovariectomy or high fat diet) to exacerbate body weight in females. Youth and sex (female) appear protective against hypertension (Blenck et al., 2016; Writing Group et al., 2016) and hypertension can be caused by higher levels of circulating AngII. Therefore, lower levels of the enzymes in the RAS pathway in females could give rise to lower AngII, providing a protective, functional significance for these differences. Sex differences in RAS components in peripheral tissues are consistent with this sex differences. For example, cardiac tissue from males has higher levels of ACE1 than is found in tissue from females (Freshour et al., 2002), and renal angiotensinogen levels are higher in males than in females (Ellison et al., 1989). Our data extend these findings to reveal the novel finding that RAS components in the brain also 
differ as a function of sex. Although others have failed to detect sex differences in RAS components centrally (Freshour et al., 2002), this was likely because whole brains were examined, rather than the discrete nuclei examined here. It is unclear why only specific brain regions showed sex- and age-related differences for specific enzymes. Future studies will be necessary to elucidate this issue.

\section{Conclusions}

For thorough understanding of both the physiological and behavioral effects of the RAS, it is critical to investigate how sex affects this system. As is true with many behaviors and physiological functions, there is a paucity in the number of reports describing how fluid intake differs between males and females. We hope this will change, and that the new NIH initiative to balance sex in biomedical research (Clayton and Collins, 2014) will help facilitate this change. The lack of information about how the sexes differ under baseline conditions may, however, confound interpretation of data. For example, until the present report, there was little guidance regarding whether or how to account for differences in body weight when interpreting fluid intake between the sexes. We show here that that multiple factors need to be considered when drawing conclusions from these comparisons. We therefore, encourage other investigators, particularly those who study ingestive behaviors, to understand how body weight may affect their output measures when incorporating females into their experimental design. As highlighted here, sex differences in opposite directions can be observed depending on how the investigators account for differences in body weight.

\section{Acknowledgments}

This work was supported by NIH grants HL091911 and DK107500 to DD and DK098841 to JS

\section{References}

Becker JB, Arnold AP, Berkley KJ, Blaustein JD, Eckel LA, Hampson E, Herman JP, Marts S, Sadee W, Steiner M, Taylor J, Young E. Strategies and methods for research on sex differences in brain and behavior. Endocrinology. 2005; 146:1650-1673. [PubMed: 15618360]

Bell DD, Zucker I. Sex differences in body weight and eating: organization and activation by gonadal hormones in the rat. Physiology \& behavior. 1971; 7:27-34. [PubMed: 5149713]

Blenck CL, Harvey PA, Reckelhoff JF, Leinwand LA. The Importance of Biological Sex and Estrogen in Rodent Models of Cardiovascular Health and Disease. Circulation research. 2016; 118:12941312. [PubMed: 27081111]

Clayton JA, Collins FS. Policy: NIH to balance sex in cell and animal studies. Nature. 2014; 509:282283. [PubMed: 24834516]

Curtis KS. Estrogen and the central control of body fluid balance. Physiology \& behavior. 2009; 97:180-192. [PubMed: 19268483]

Curtis KS, Contreras RJ. Sex differences in electrophysiological and behavioral responses to $\mathrm{NaCl}$ taste. Behavioral neuroscience. 2006; 120:917-924. [PubMed: 16893297]

Daniels, D., Fluharty, SJ. Neuroendocrinology of Body Fluid Homeostasis. In: Pfaff, DW.AP, A.Etgen, AM.Fahrbach, SE., Rubin, RT., editors. Hormones Brain and Behavior. 2. Academic Press; San Diego: 2009. p. 259-288.

Danielsen J, Buggy J. Depression of ad lib and angiotensin-induced sodium intake at oestrus. Brain research bulletin. 1980; 5:501-504. [PubMed: 7191763]

Davis JD. The microstructure of ingestive behavior. Annals of the New York Academy of Sciences. 1989; 575:106-119. discussion 120-101. [PubMed: 2699182] 
Davis JD, Smith GP, Singh B. A microstructural analysis of the control of water and isotonic saline ingestion by postingestional stimulation. Physiology \& behavior. 1999; 66:543-548. [PubMed: 10357447]

Ellison KE, Ingelfinger JR, Pivor M, Dzau VJ. Androgen regulation of rat renal angiotensinogen messenger RNA expression. The Journal of clinical investigation. 1989; 83:1941-1945. [PubMed: 2723066]

Engelbregt MJ, van Weissenbruch MM, Lips P, van Lingen A, Roos JC, Delemarre-van de Waal HA. Body composition and bone measurements in intra-uterine growth retarded and early postnatally undernourished male and female rats at the age of 6 months: comparison with puberty. Bone. 2004; 34:180-186. [PubMed: 14751576]

Epstein AN, Fitzsimons JT, Rolls BJ. Drinking induced by injection of angiotensin into the rain of the rat. The Journal of physiology. 1970; 210:457-474. [PubMed: 4322723]

Evered MD, Robinson MM, Rose PA. Effect of arterial pressure on drinking and urinary responses to angiotensin II. The American journal of physiology. 1988; 254:R69-74. [PubMed: 3337271]

Fischer M, Baessler A, Schunkert H. Renin angiotensin system and gender differences in the cardiovascular system. Cardiovascular research. 2002; 53:672-677. [PubMed: 11861038]

Fitzsimons JT, Simons BJ. The effect on drinking in the rat of intravenous infusion of angiotensin, given alone or in combination with other stimuli of thirst. The Journal of physiology. 1969; 203:45-57. [PubMed: 4309726]

Flynn FW, Schulkin J, Havens M. Sex differences in salt preference and taste reactivity in rats. Brain research bulletin. 1993; 32:91-95. [PubMed: 8348348]

Freshour JR, Chase SE, Vikstrom KL. Gender differences in cardiac ACE expression are normalized in androgen-deprived male mice. American journal of physiology Heart and circulatory physiology. 2002; 283:H1997-2003. [PubMed: 12384478]

Guyton AaH, JE. Textbook of Medical Physiology. Philadelphia, PA: 2006.

Hsiao S, Epstein AN, Camardo JS. The dipsogenic potency of peripheral angiotensin II. Hormones and behavior. 1977; 8:129-140. [PubMed: 558956]

Jarrar D, Wang P, Cioffi WG, Bland KI, Chaudry IH. The female reproductive cycle is an important variable in the response to trauma-hemorrhage. American journal of physiology. Heart and circulatory physiology. 2000; 279:H1015-1021. [PubMed: 10993763]

Jonklaas J, Buggy J. Angiotensin-estrogen interaction in female brain reduces drinking and pressor responses. The American journal of physiology. 1984; 247:R167-172. [PubMed: 6742227]

Jonklaas J, Buggy J. Angiotensin-estrogen central interaction: localization and mechanism. Brain research. 1985; 326:239-249. [PubMed: 3971153]

Kaufman S. A comparison of the dipsogenic responses of male and female rats to a variety of stimuli. Canadian journal of physiology and pharmacology. 1980; 58:1180-1183. [PubMed: 7470990]

Krause EG, Curtis KS, Davis LM, Stowe JR, Contreras RJ. Estrogen influences stimulated water intake by ovariectomized female rats. Physiology \& behavior. 2003; 79:267-274. [PubMed: 12834798]

Krecek J. Sex differences in salt taste: the effect of testosterone. Physiology \& behavior. 1973; 10:683688. [PubMed: 4708981]

Krecek J, Novakova V, Stibral K. Sex differences in the taste preference for a salt solution in the rat. Physiology \& behavior. 1972; 8:183-188. [PubMed: 4677204]

Overpeck JG, Colson SH, Hohmann JR, Applestine MS, Reilly JF. Concentrations of circulating steroids in normal prepubertal and adult male and female humans, chimpanzees, rhesus monkeys, rats, mice, and hamsters: a literature survey. Journal of toxicology and environmental health. 1978; 4:785-803. [PubMed: 104044]

Richter CP, Brailey ME. Water-Intake and Its Relation to the Surface Area of the Body. Proceedings of the National Academy of Sciences of the United States of America. 1929; 15:570-578. [PubMed: 16587493]

Robinson MM, Evered MD. Pressor action of intravenous angiotensin II reduces drinking response in rats. The American journal of physiology. 1987; 252:R754-759. [PubMed: 3551636]

Santollo J, Daniels D. Activation of G protein-coupled estrogen receptor 1 (GPER-1) decreases fluid intake in female rats. Hormones and behavior. 2015a; 73:39-46. [PubMed: 26093261] 
Santollo J, Daniels D. Control of fluid intake by estrogens in the female rat: role of the hypothalamus. Frontiers in systems neuroscience. 2015b; 9:25. [PubMed: 25788879]

Santollo J, Eckel LA. The orexigenic effect of melanin-concentrating hormone (MCH) is influenced by sex and stage of the estrous cycle. Physiology \& behavior. 2008; 93:842-850. [PubMed: 18191424]

Santollo J, Marshall A, Curtis KS, Speth RC, Clark SD, Daniels D. Divergent effects of ERalpha and ERbeta on fluid intake by female rats are not dependent on concomitant changes in AT1R expression or body weight. American journal of physiology Regulatory, integrative and comparative physiology. 2016; 311:R14-23.

Sun Z, Fregly MJ, Rowland NE, Cade JR. Comparison of changes in blood pressure and dipsogenic responsiveness to angiotensin II in male and female rats chronically exposed to cold. Physiology \& behavior. 1996; 60:1543-1549. [PubMed: 8946503]

Tarttelin MF, Gorski RA. Variations in food and water intake in the normal and acyclic female rat. Physiology \& behavior. 1971; 7:847-852. [PubMed: 5167385]

Tatchum-Talom R, Eyster KM, Martin DS. Sexual dimorphism in angiotensin II-induced hypertension and vascular alterations. Canadian journal of physiology and pharmacology. 2005; 83:413-422. [PubMed: 15897923]

Thunhorst RL, Beltz TG, Johnson AK. Drinking and arterial blood pressure responses to ANG II in young and old rats. American journal of physiology. Regulatory, integrative and comparative physiology. 2010; 299:R1135-1141.

Thunhorst RL, Beltz TG, Johnson AK. Effects of aging on mineralocorticoid-induced salt appetite in rats. American journal of physiology Regulatory, integrative and comparative physiology. 2013; 305:R1498-1505.

Thunhorst RL, Johnson AK. Thirst and salt appetite responses in young and old Brown Norway rats. American journal of physiology Regulatory, integrative and comparative physiology. 2003; 284:R317-327.

Vijande M, Costales M, Schiaffini O, Marin B. Angiotensin-induced drinking: sexual differences. Pharmacology, biochemistry, and behavior. 1978; 8:753-755.

Wolden-Hanson T, Marck BT, Smith L, Matsumoto AM. Cross-sectional and longitudinal analysis of age-associated changes in body composition of male Brown Norway rats: association of serum leptin levels with peripheral adiposity. The journals of gerontology Series A, Biological sciences and medical sciences. 1999; 54:B99-107.

Writing Group M; Mozaffarian D, Benjamin EJ, Go AS, Arnett DK, Blaha MJ, Cushman M, Das SR, de Ferranti S, Despres JP, Fullerton HJ, Howard VJ, Huffman MD, Isasi CR, Jimenez MC, Judd SE, Kissela BM, Lichtman JH, Lisabeth LD, Liu S, Mackey RH, Magid DJ, McGuire DK, Mohler ER 3rd, Moy CS, Muntner P, Mussolino ME, Nasir K, Neumar RW, Nichol G, Palaniappan L, Pandey DK, Reeves MJ, Rodriguez CJ, Rosamond W, Sorlie PD, Stein J, Towfighi A, Turan TN, Virani SS, Woo D, Yeh RW, Turner MB, American Heart Association Statistics C Stroke Statistics S. Executive Summary: Heart Disease and Stroke Statistics-2016 Update: A Report From the American Heart Association. Circulation. 2016; 133:447-454. [PubMed: 26811276]

Xue B, Johnson AK, Hay M. Sex differences in angiotensin II-induced hypertension. Brazilian journal of medical and biological research $=$ Revista brasileira de pesquisas medicas e biologicas. 2007a; 40:727-734. [PubMed: 17464437]

Xue B, Johnson AK, Hay M. Sex differences in angiotensin II- and aldosterone-induced hypertension: the central protective effects of estrogen. American journal of physiology Regulatory, integrative and comparative physiology. 2013; 305:R459-463.

Xue B, Pamidimukkala J, Hay M. Sex differences in the development of angiotensin II-induced hypertension in conscious mice. American journal of physiology Heart and circulatory physiology. 2005; 288:H2177-2184. [PubMed: 15626687]

Xue B, Pamidimukkala J, Lubahn DB, Hay M. Estrogen receptor-alpha mediates estrogen protection from angiotensin II-induced hypertension in conscious female mice. American journal of physiology Heart and circulatory physiology. 2007b; 292:H1770-1776. [PubMed: 17142339] 


\section{Highlights}

- Males drank more water in response to AngII compared to females.

- $\quad$ The sex difference in water intake was related to postingestive feedback.

- In males, but not females, body weight predicted intake after high doses of AngII.

- Brain expression of RAS-associated genes varied as a function of sex. 
A
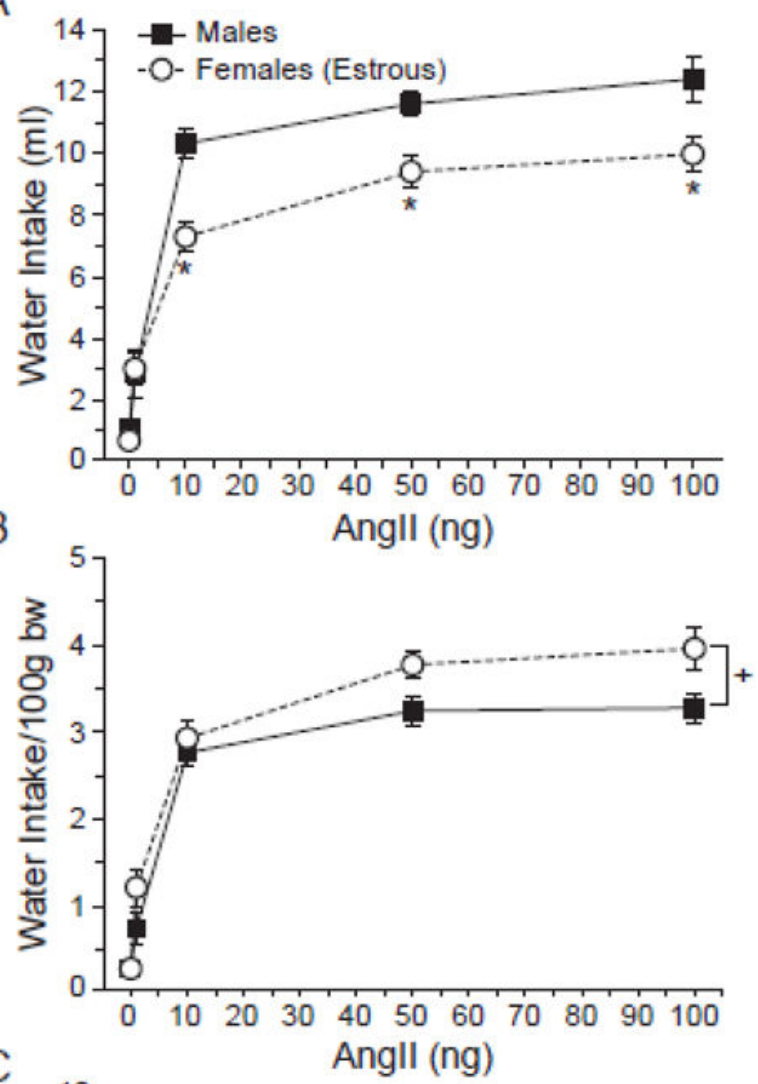

$\mathrm{C}$

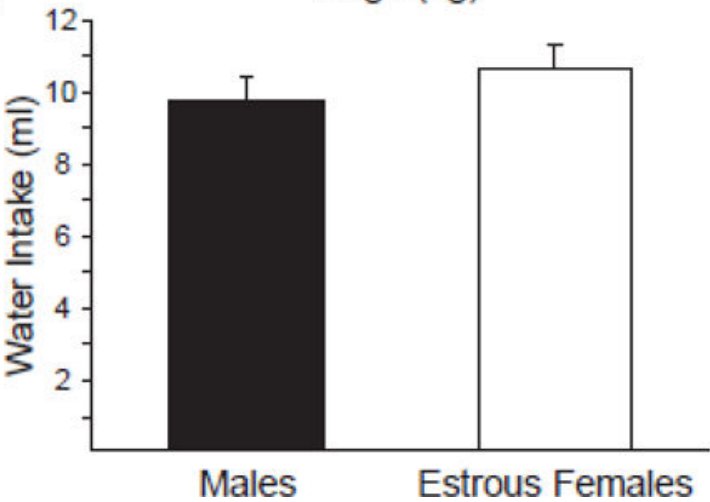

Figure 1.

Sex differences in water intake after i.c.v. AngII treatment. (A) Males drank more than estrous females after treatment with 10, 50 and 100ng AngII. (B) When intake was normalized to body weight, females drank more than males regardless of AngII dose. (C) There was no difference in water intake after i.c.v. treatment of 100ng AngII in $285 \mathrm{~g}$ male and estrous females. *Less than males at this dose. +Greater than males. 

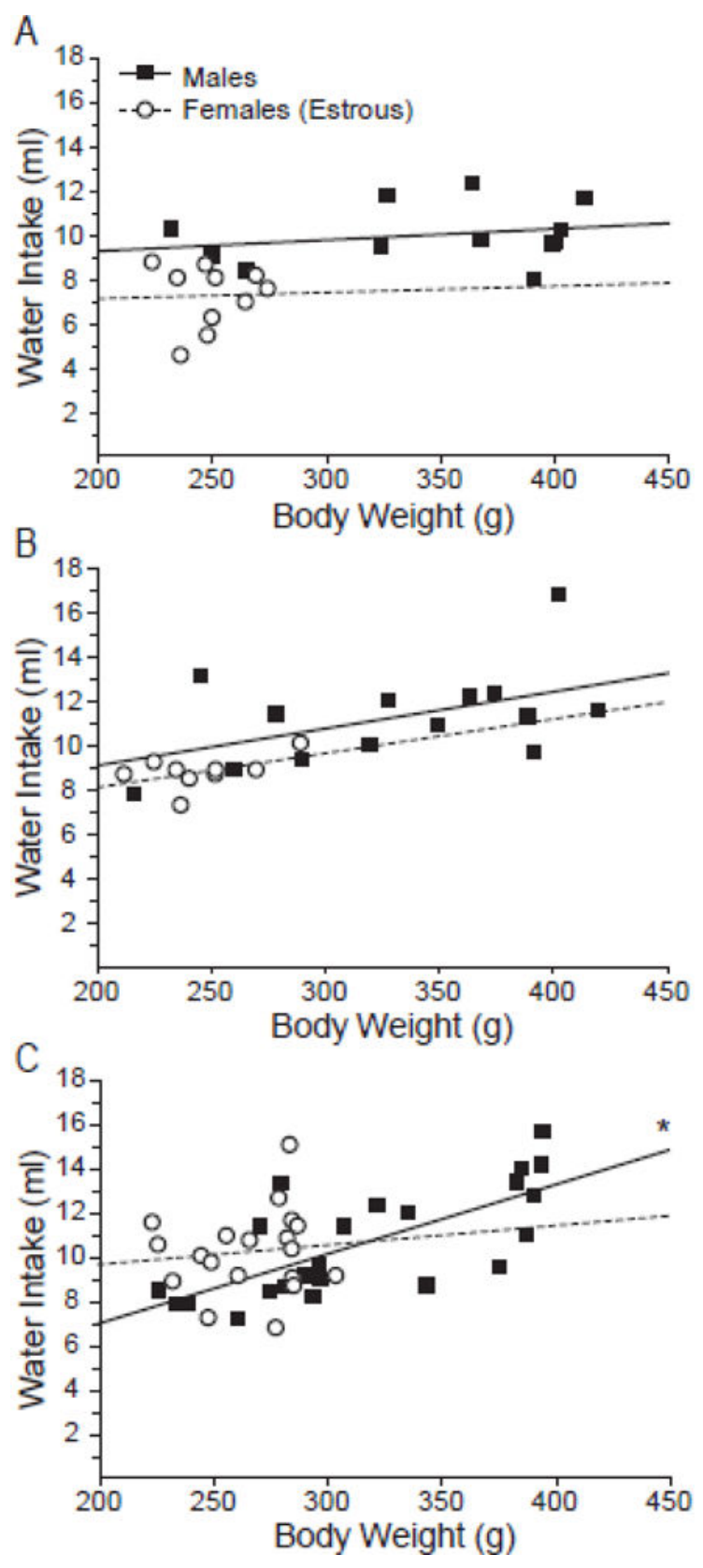

Figure 2.

Relationship between intake and body weight after AngII in males and estrous females. (A)

Body weight did not predict water intake after 10ng AngII treatment in either males or estrous females. (B) Similarly, body weight did not predict water intake after 50ng AngII treatment in either males or estrous females. (C) There was a significant positive relationship between body weight and water intake after 100ng AngII treatment in males but not in estrous females. Furthermore, the regression coefficient between body weight and water intake was significantly different between males and estrous females. *Regression coefficient greater than estrous females.

Horm Behav. Author manuscript; available in PMC 2018 July 01. 


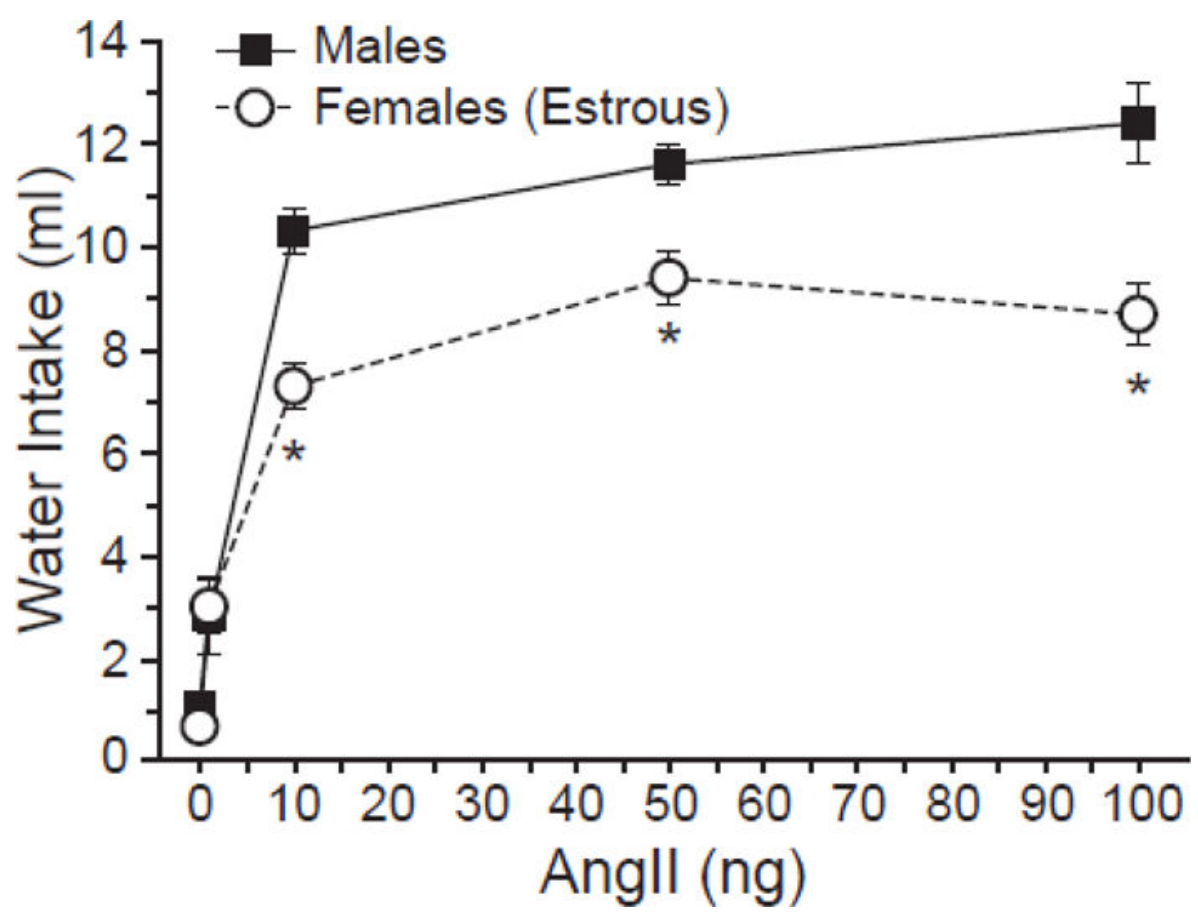

Figure 3.

Dose response curves for AngII after correcting 100ng AngII intake for baseline differences. Males drank more water than did estrous females after treatment with 10,50 and 100ng AngII. *Greater than estrous females. 

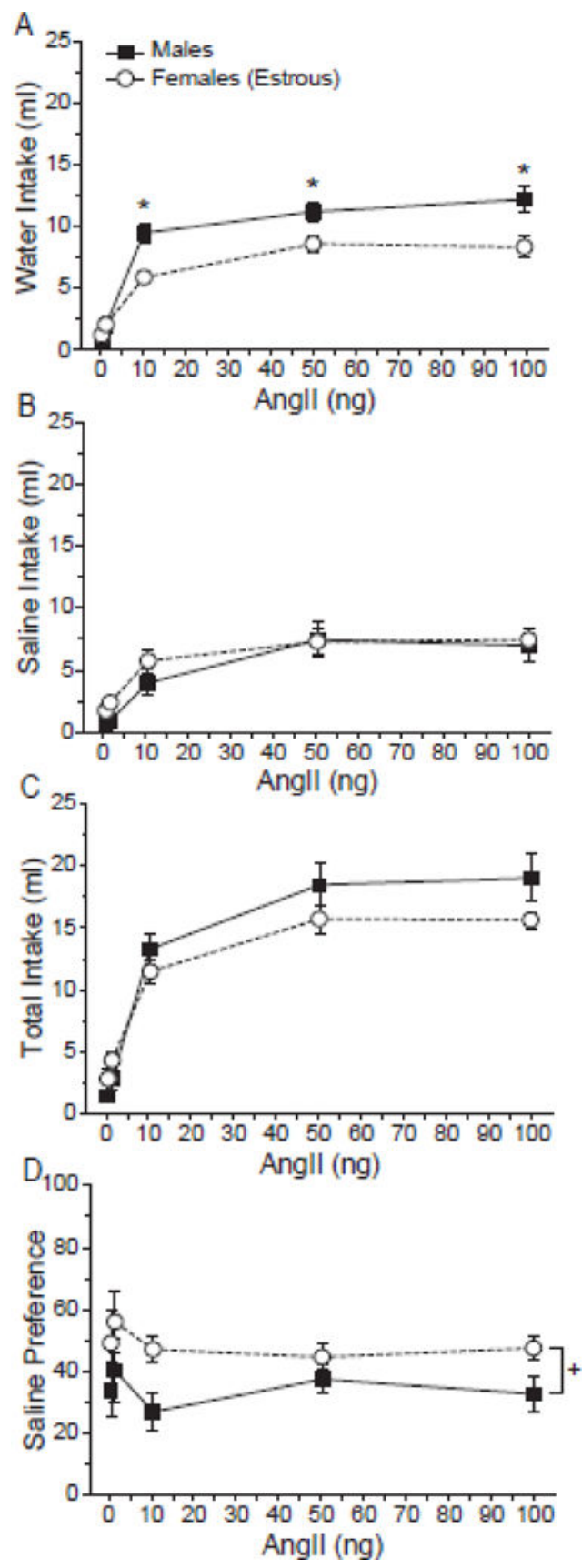

Figure 4.

Sex differences in water and $1.5 \%$ saline intake after AngII. (A) Males drank more water than estrous females after treatment with 10, 50 and 100ng AngII. (B) There was no difference in $1.5 \%$ saline intake between males and estrous females after any dose of AngII. Regardless of sex, intake after treatment with 10ng was higher than intake after 0 and 1 ng. Intake after treatment with 50 and 100ng was higher than intake after 10ng. (C) There was no difference in total fluid intake between males and estrous females after any dose of AngII. Again, regardless of sex, intake after treatment with 10ng was higher than intake after 0 and 1 ng. Intake after treatment with 50 and 100ng was higher than intake after 10ng. (D)

Horm Behav. Author manuscript; available in PMC 2018 July 01. 
Regardless of AngII dose, estrous females showed a greater preference for 1.5\% saline than males. *Greater than estrous females. +Greater than males. 

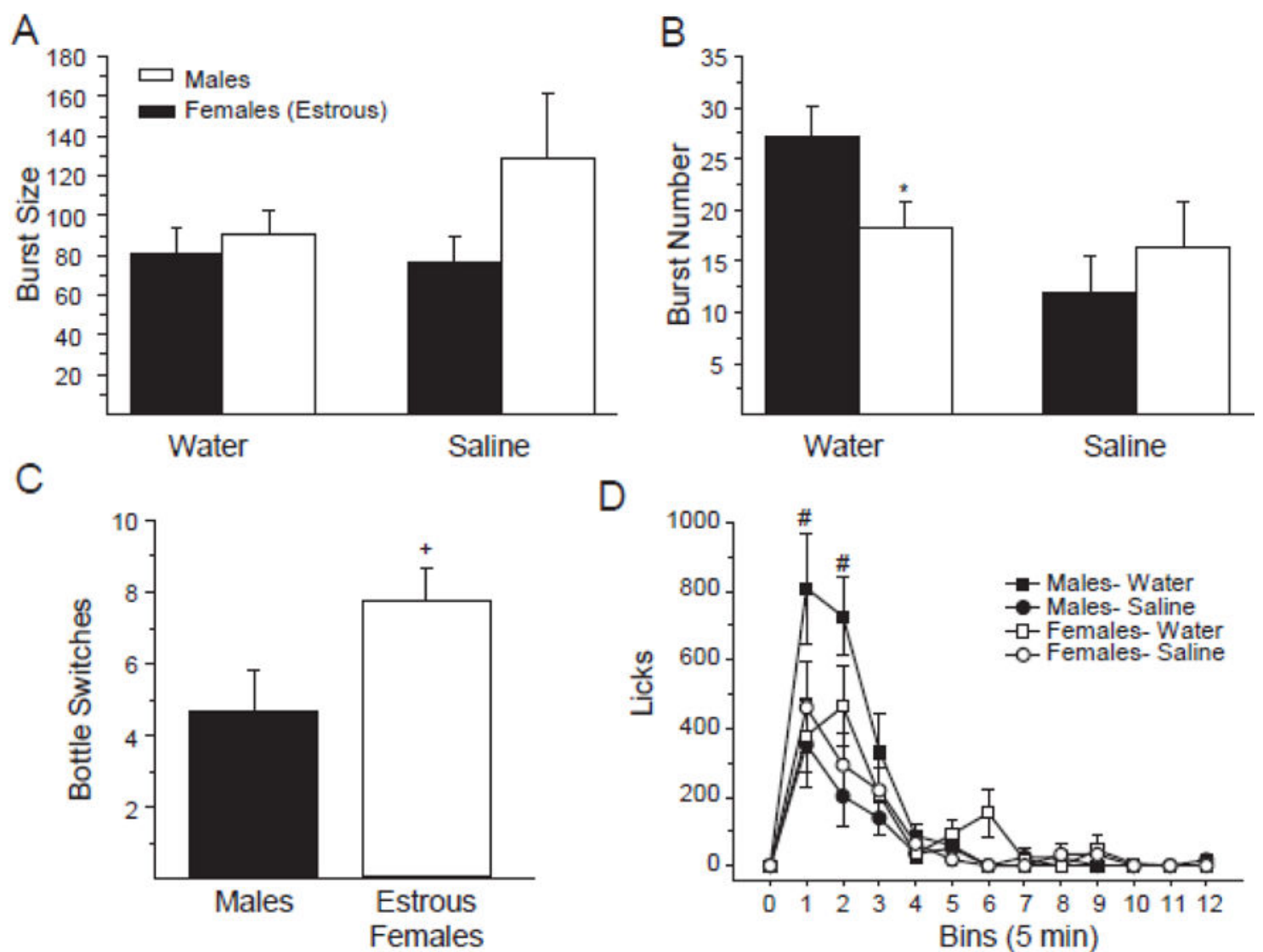

Figure 5.

Sex differences in drinking microstructure for AngII-stimulated water and $1.5 \%$ saline. (A) Burst size for water and $1.5 \%$ saline were similar between males and estrous females. (B) The number of bursts for water was greater in males than estrous females; however, there was no difference in the number of bursts for saline between the sexes. (C) Estrous females made more switches between the water and $1.5 \%$ saline bottles than did males. (D) Across the test period, the number of licks for water by males was greater than the number of licks for saline. The number of licks for water by males was also higher than the number of licks for water or for saline by females during the first two 5-min bins. *Less than males. + Greater than males. \#Greater than all other groups. 
Table 1

Primer sequences for qPCR

\begin{tabular}{|l|l|l|}
\hline Gene & Forward Primer & Reverse Primer \\
\hline AT1R & CGGCCTTCGGATAACATGA & CCTGTCACTCCACCTCAAAACA \\
\hline ACE1 & GTGTTGTGGAACGAATACGC & CCTTCTTTATGATCCGCTTGA \\
\hline ACE2 & GTGGAGGTGGATGGTCTTTCA & TTGGTCCACTGTTCTCTGGGA \\
\hline Renin & CCACCTTCATCCGCAAGTTC & TGCGATTGTTATGCCGGTC \\
\hline $18 \mathrm{~s}$ & CACGGGTGACGGGGAATCAG & CGGGTCGGGAGTGGGTAATTTG \\
\hline
\end{tabular}




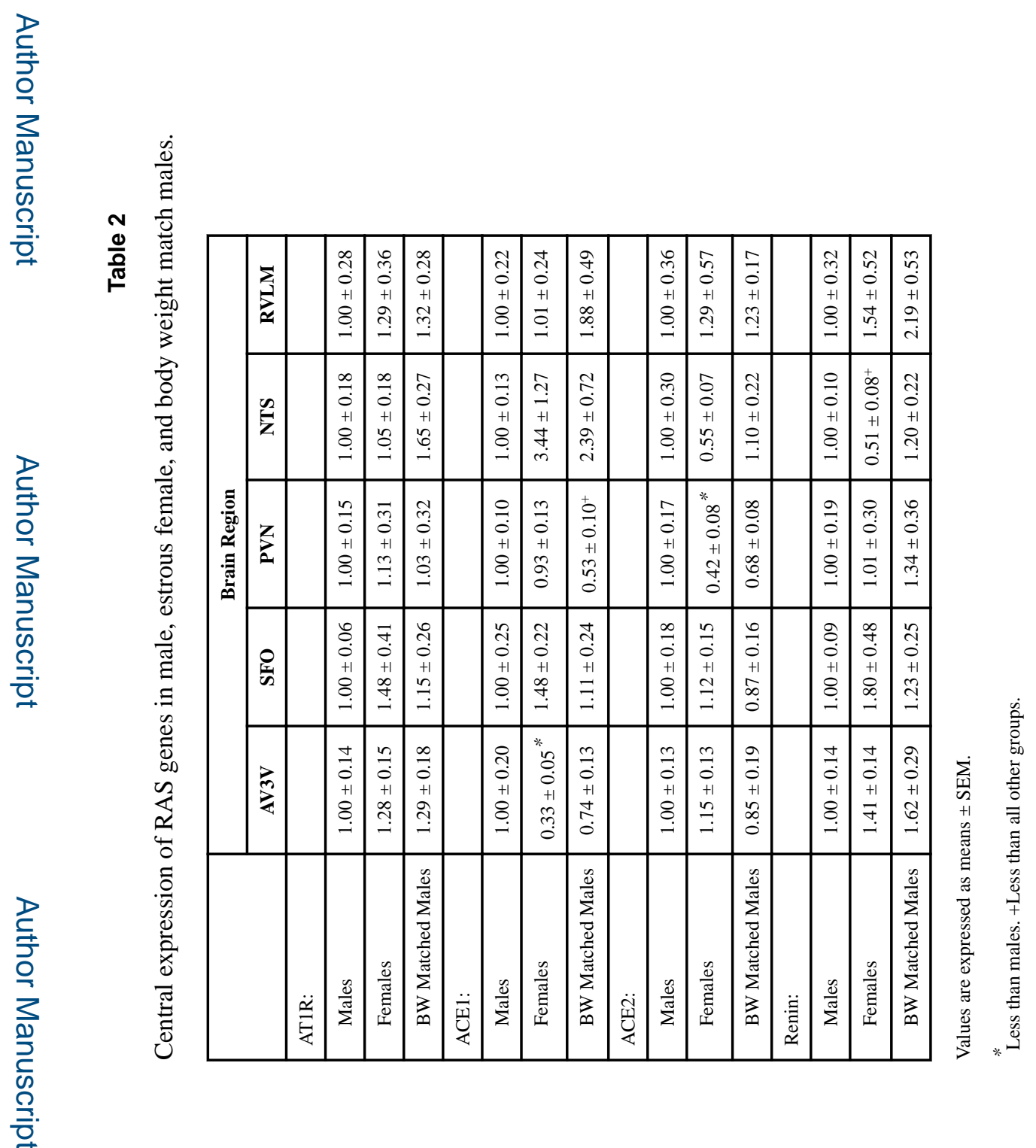

Horm Behav. Author manuscript; available in PMC 2018 July 01. 